\title{
Stochastic Numerical Simulation for the Evaluation of Mechanical Properties of Filled Polymer Composites
}

\author{
Supriya SUBRAMANIAM ${ }^{1}$, Krishnaveni ANBALAGAN ${ }^{1}{ }^{*}$, Selwinrajadurai JEYARAJ ${ }^{1}$, \\ Selvakumar MURUGAN ${ }^{2}$
}

${ }^{1}$ Department of Mechanical Engineering, Government College of Engineering, Tirunelveli - 627007 India
${ }^{2}$ Department of Mechanical Engineering, Government College of Engineering, Tirunelveli - 627007 India

crossref http://dx.doi.org/10.5755/j01.ms.23.1.14217

Received 20 February 2016; accepted 03 June 2016

\begin{abstract}
Reinforced polymeric composites are profoundly used in variety of applications due to its high strength to weight ratio and ease of fabrication. The wide spread application of reinforced polymeric materials in the electronic industries have created a great demand in fabricating a kind of reinforced polymeric system, which is light but has better mechanical strength and good thermal properties. Especially glass microsphere filled epoxy resin composites is used as a potting compound in electronic and aviation industries. Therefore, knowledge of the fundamental thermal and mechanical properties of these systems is highly essential in the formulation of advanced electronic potting compounds. In this work, the effective mechanical properties of glass microsphere filled epoxy system is investigated numerically by stochastic simulation. Numerical simulation software ANSYS is used to characterise the microstructure of the filled epoxy system. MATLAB code has been developed to model the randomness of the particle. The geometric model generated from the MATLAB code is given as an input to ANSYS. Random particle Representative Volume Element (RVE) model is used to evaluate the mechanical properties at various loading fractions. The effect of particle size on mechanical properties of glass microsphere filled epoxy composite is studied. Further the random RVE modeling scheme is compared with single RVE modeling scheme and its significance is reported. The numerically predicted values of effective modulus is then compared with the analytical models and with the literature experimental data. Also the significance of the analytical model on the determination of properties is reported. Then, the effect of interface on the mechanical characterisation by stochastic model is analysed and the debonding of the particle is also simulated.

Keywords: stochastic, potting compound, glass microsphere, loading fractions, representative volume element and analytical model.
\end{abstract}

\section{INTRODUCTION}

Particulate composite materials have been intensively developed since 1960 and have shown rapid development in the electronics and aviation industries for the past decades. These materials are highly preferred because of its tailorable characteristics. Depending on the type of particle that is filled in polymer matrix, outstanding properties are achieved. Besides strengthening up the composite, particles also be enough to modify the creep, impact, hygral, thermal, electrical and magnetic properties as well as wear resistance, inflammability and other such properties of the composite. Most of the researchers have claimed that the mechanical and thermal property are improved by the addition of filler in micrometer to nanometer sizes [ $1-6]$. Some of the fillers, which have shown dramatic improvements in the properties are silicon dioxide, glass, aluminium oxide, copper, carbon nano tubes, and carbon nano fibre and so on. Among these fillers, the glass microsphere is commonly used for improvement in high modulus, relatively high strength, fracture toughness, low coefficient of expansion and low cost [5-7]. These are the demandable qualities of an electronic potting compound. Therefore, the glass bead filled epoxy system is best suited for electronic applications $[8,9]$. Thus in designing composite structures, it is necessary to determine the effective properties of the composite and understand responses of the constituents when the composite is subjected to various external stimuli.

Conducting experiments to obtain the effective response of composites under various loading histories and at different compositions and properties of the constituents is often costly and time consuming. Modelling response of composites that include detailed micro structural characteristics allows obtaining macroscopic response of the structural components and detailed response of the constituents. However, it is impossible to incorporate detailed characteristics of the constituents and microstructural geometries in designing and analysing response of the composite structures. Many researchers have experimentally determined the mechancial properties of filled polymeric composites [10-13]. Matthew Quesenberry et al. [14], have experimentally studied the characteristics of low density glass filled epoxies on density, co-efficient of thermal expansion and composite modulus. A comparative experimental study has been made between solid glass filler, hollow glass filler and combination of both solid and hollow filler for various volume fractions. The authors [15] have reviewed the literature experimental data and reported that there is a strong dependence of the effects of particle size, particle/matrix interface adhesion and particle loading

\footnotetext{
* Corresponding author. Tel.: +91- 9894182237.

E-mail address: krishnaveni@gcetly.ac.in (A.Krishnaveni)
} 
fractions on the stiffness, strength and toughness of particulate composites. Experimental studies have also been made using nano filled polymer composites [16, 17] and empirical relations for mechanical properties in terms of volume fraction of filler have been suggested [17]. Numerical studies have been made for addressing the effect of interface, particle size, particle shape and loading fraction on nano composites by using 3D multi particle unit cell on mechanical properties [18]. A special program for the automatic generation of 2D random distribution particles without overlapping has been developed by Zhenqing et al. [19] based on Monte carlo simulation technique for nano silica composite with regard to the effective modulus and ultimate stress and have compared simulation results with experimental data.

The literatures reviewed have focussed the importance of particle reinforced composites and determination of its properties experimentally. Only few of the researchers $[16,17]$ have focussed the need for numerical simulation in the prediction of mechanical and thermal properties. Numerical Studies reported have been carried out having an assumption of periodic dispersion of particles and the randomness in the particle distribution is scarcely reported. In this work, an attempt is made to predict the effective mechanical properties such as modulus and tensile strength for Solid Glass Microsphere (SGM) filled epoxy composite numerically using finite element software Ansys in 2D. The numerical model considered in this study include single RVE and random RVE. Further the effect of particle size, particle bonding and loading fraction on the mechanical properties is investigated using stochastic numerical simulation. The numerical studies carried out in this work is compared with the established empirical relation and with the literature experimental data [14].

\section{THEORETICAL MODELS}

Growing demand towards the use of particle filled composites in various applications such as building materials, space flight and aviation industry emphasises its importance in the evaluation of thermal, mechanical and dielectric property of the system. The geometry of the particle, individual constituent properties, distribution of particle within the matrix medium and interface between the particles are the key factors upon which a binary or ternary composite system relies on, in the prediction of its effective properties. Though the properties can be measured by experimental methods, analytical methods and equations are highly essential to predict the properties of composite materials in order to have a better understanding of the micromechanics of the composite materials as well as to cut down the experimentation cost. Numerous models have been developed over the last century for determining the effective properties of two-phase composites. The models that were developed have assumed particle geometry, particle distribution and complete interfacial contact between the two phases.

This section reviews some of the important theoretical/empirical models reported in the literature for evaluating the effective Young's modulus and strength of particle filled composites. The Voigt and Reuss models are the two most basic models used to characterise the mechanical behaviour of a two-phase composite system consisting of a spherical filler inclusion embedded in a continuous matrix material. The Voigt and Reuss model, described by Eq. 1 and Eq. 2, assumes that the particulate inclusions and matrix material are subjected to constant strain and constant stress respectively:

Voigt model $E_{c}=E_{m} V_{m}+E_{f} V_{f}$;

Reuss model $\quad E_{c}=\frac{E_{m} E_{f}}{E_{m} V_{f}+E_{f} V_{m}}$.

In addition to the Voigt and Reuss model, other theoretical models to predict the effective Young's modulus of the composite system proposed by Neilson and Einstein are given in the Eq. 3 and Eq. 4:

Neilson's model $E_{c}=E_{m}\left(1+2.5 V_{f}\right)$;

Einstein's model $E_{c}=E_{m}\left(1+V_{f}\right)$,

where $E_{f}, E_{m}, E_{c}$ are Young's modulus of filler, matrix and composite respectively and $V_{f}, V_{m}$ are volume fraction of filler and matrix respectively.

It is impossible to specify the conditions of constant stress or strain across the filler-matrix boundaries, hence more rigorous models have been proposed using bounding relationships or self-consistent field theories ${ }^{[20]}$ to increase the predictive accuracy of the Voigt and the Reuss models. The modulus properties of the glass filled composites are modeled using the S-Combining Rule given in Eq. 5 - Eq. 9 .

S-Combining rule

$\frac{1}{s_{c}}=\frac{V_{m}}{s_{l}}+\frac{v_{f}}{s_{u}}+\gamma V_{f} V_{m}\left(\frac{1}{s_{l}}-\frac{1}{s_{u}}\right) ;$

$\mathrm{S}_{\mathrm{u}}=\mathrm{S}_{\mathrm{f}}\left[1+\left(\frac{\mathrm{V}_{\mathrm{m}}\left(\mathrm{S}_{\mathrm{m}}-\mathrm{S}_{\mathrm{f}}\right)}{\mathrm{S}_{\mathrm{f}}+\mathrm{V}_{\mathrm{f}}\left(\mathrm{S}_{\mathrm{m}}-\mathrm{S}_{\mathrm{f}}\right)\left(1-\eta_{\mathrm{sf}}\right)}\right)\right]$

$S_{l}=S_{m}\left[1+\left(\frac{V_{f}\left(s_{m}-S_{f}\right)}{S_{m}-V_{m}\left(S_{m}-S_{f}\right)\left(1-\eta_{s m}\right)}\right)\right]$,

where the parameters $S_{\mathrm{f}}, S_{\mathrm{m}}$ and $S_{\mathrm{c}}$ are bulk modulus of filler, matrix and composite respectively. $\eta_{\mathrm{sf}}$ and $\eta_{\mathrm{sm}}$ defined by

$\eta_{s j}=\frac{2\left(4-5 \vartheta_{j}\right)}{15\left(1-\vartheta_{j}\right)}$

where $j=\operatorname{matrix}(\mathrm{m})$ or the filler $(f)$ and $\vartheta_{j}$ represents Poisons ratio

$\gamma=$ phase continuity parameter

$\gamma=\frac{2 \varphi_{c}-1}{\varphi_{c}}$

$\varphi_{c}=2 / 3$ for spherical filler.

The C-Combining Rule is shown in Eq. 10-Eq.13. This rule is more appropriate for the matrix filled with a more compliant filler, such as epoxy matrix loaded with hollow glass spheres (i.e., $E_{\mathrm{f}}<E_{\mathrm{m}}$ ).

$P_{c}=V_{m} P_{u}+V_{f} P_{l}+\lambda_{p} V_{f} V_{m}\left(P_{u}-P_{l}\right)$,

where, $\lambda \mathrm{p}=$ phase continuity parameter and $P=$ bulk modulus $(k)$ or shear modulus $(G)$ and subscripts $\mathrm{f}, \mathrm{m}$ and c denotes filler, matrix and composite respectively.

$P_{l}=P_{f}\left[1+\left(\frac{V_{m}\left(P_{m}-P_{f}\right)}{P_{f}-V_{f}\left(P_{m}-P_{f}\right)\left(\eta_{P f}\right)}\right)\right] ;$
$P_{u}=P_{m}\left[1-\left(\frac{V_{f}\left(P_{m}-P_{f}\right)}{P_{m}-V_{m}\left(P_{m}-P_{f}\right)\left(\eta_{P m}\right)}\right)\right] ;$ 
$\lambda_{p}=\frac{2 \varphi_{c}-1}{\varphi_{c}\left[1-2 \varphi_{c}\left(1-\varphi_{c}\right) \eta_{P m}\right]}$

The tensile strength of particle filled composites are evaluated by analytical models given in Eq.14 and Eq.15:

Tavmans model $\sigma_{c}=\sigma_{m}\left(1-b V_{f}^{2 / 3}\right)$;

$b=1.21$ for Spherical particles

Wongs model $\sigma_{c}=\sigma_{m}\left(1-b V_{f}^{2 / 3}\right)$,

where $b=0.5$ for lower concentration of fillers, $\sigma_{c}$, $\sigma_{m}$ are tensile strength of composite and matrix respectively.

\section{MATERIALS AND METHODS}

Recently, the need to predict the effective properties of the particle filled composite in an efficient way has drawn the attention of the researchers due to its wide spread application. The way in which the microstructural characteristics are modeled is the major influencing criteria in the prediction of effective properties of the particulate composite. Hence one need to exactly model the microstructure of the particle filled composites. Finite element analysis is one of the numerical tool which provides an approximate solution quickly for any complex engineering problems. In this work, the finite element software ANSYS is used for the investigation of modeling scheme of particle filled epoxy composite. The particle considered in this study is SGM. The material properties of the filler and the matrix considered in this study are shown in the Table 1.

Table 1. Material properties

\begin{tabular}{|l|l|l|}
\hline \multirow{2}{*}{ Property } & \multicolumn{2}{c|}{ Material } \\
\cline { 2 - 3 } & Epoxy & \multicolumn{1}{|c|}{ SGM } \\
\hline Density, g/cm ${ }^{3}$ & 1.19 & 2.54 \\
\hline Young's modulus, GPa & 2.45 & 76 \\
\hline Poisson's ratio & 0.33 & 0.23 \\
\hline Rigidity modulus, GPa & 0.92 & 30.9 \\
\hline Bulk modulus, GPa & 2.47 & 46.9 \\
\hline Thermal conductivity, $\mathrm{KW} /(\mathrm{m} \cdot \mathrm{K})$ & 0.363 & 0.00363 \\
\hline
\end{tabular}

This numerical investigation of SGM filled epoxy composite addresses the effect of particle loading fraction of $\operatorname{SGM}(5,10,15$ and $20 \%)$, particle radius $(12.5,15,20$ and $25 \mu \mathrm{m}$ ), particle bonding (Perfect bonding) and critical length on the tensile behaviour of filled polymer composites by Stochastic based Numerical Simulation.

\subsection{Stochastic/random RVE}

The algorithm for generation of stochastic or random RVE as shown in the Fig. 1 has the following steps.

1. Generation of RVE which should be small enough to distinguish microscopic heterogeneities, but sufficiently large to represent the overall behaviour of the heterogeneous medium.

2. Generate random location of particles.

3. The random size of the particle in the RVE is based on the assumption that it represents the particle in a slicing plane anywhere within 3D model.

A MATLAB code has been developed for the generation of random non-overlapping circles that satisfies the required area fraction. During the execution of
MATLAB code, the random location generated are checked with the two constraints i.e. they should lie within the RVE and the minimum distance between the two centre should be equal to the diameter of the particle. The X, Y co-ordinates for center of the circle as well as the radii are taken from the MATLAB output. The Fig. 2 shows MATLAB output of N number of non-overlapping circles with random radii that satisfies the required area fraction. For various particle loading fraction, the $\mathrm{X}, \mathrm{Y}$ co-ordinates of the particle center and its radius is obtained and imported to ANSYS for analysis.

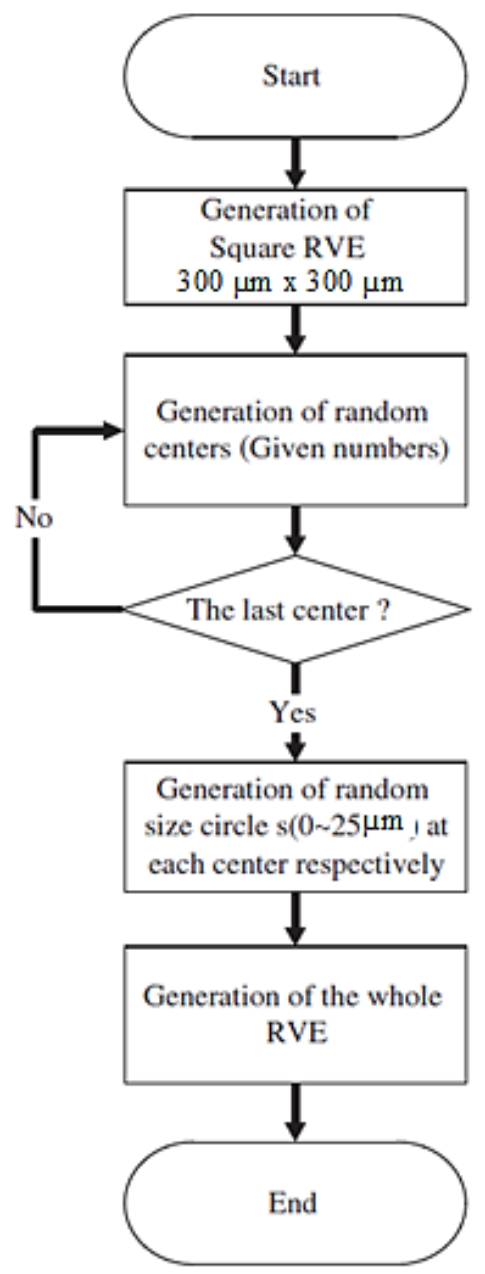

Fig. 1. Algorithm for the generation of RVE of $300 \mu \mathrm{m} \times 300 \mu \mathrm{m}$ size with randomly filled SGM particles

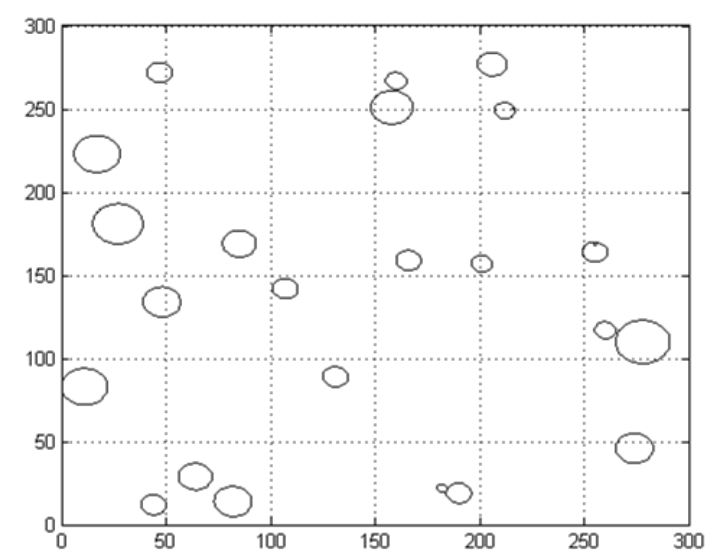

Fig. 2. MATLAB output of $N$ number of non-overlapping circles with random radii for a specific area fraction 


\subsection{Structural analysis}

Initially, the structural analysis of a single RVE as shown in Fig. 3 has been carried out to evaluate the mechanical properties of the particle filled composite. Basic assumption behind this model is periodic distribution of filler particles, where the filler particles are evenly distributed in the matrix. In the numerical analysis of filled polymer composites both the periodic arrangement model and single RVE model predicts the same result [21].

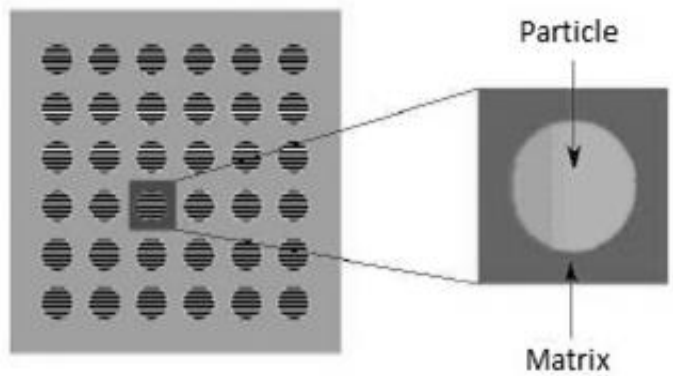

Fig. 3. Geometry showing the periodic arrangement of particle filled in epoxies

Hence in this work, single RVE model is considered for structural analysis. In Single RVE model, the geometry took advantage of symmetry and therefore is modelled as onequarter of a two dimensional unit cell with the calculated dimensions. The unit cell consists of particle and matrix material. The characteristic length of the model for various volume fractions of SGM-epoxy is calculated and PLANE183 element is used for the structural analysis.

Mesh convergence is carried out to determine the number of parts to be divided for which the consistency of the adopted mesh with problem domain geometry is maintained. The Fig. 4 shows the mesh convergence plot in the evaluation of elastic modulus by finite element method. The material properties for epoxy and fillers are given in meshing attributes. The boundary conditions and the load imposed on the single RVE model is as shown in Fig. 5 and the structural analysis is performed. Further the analysis is repeated, for various loading fractions of SGM and compared with literature experimental data. Then the numerical analysis is carried out by considering the random location of the particle i.e. random RVE or stochastic modelling.

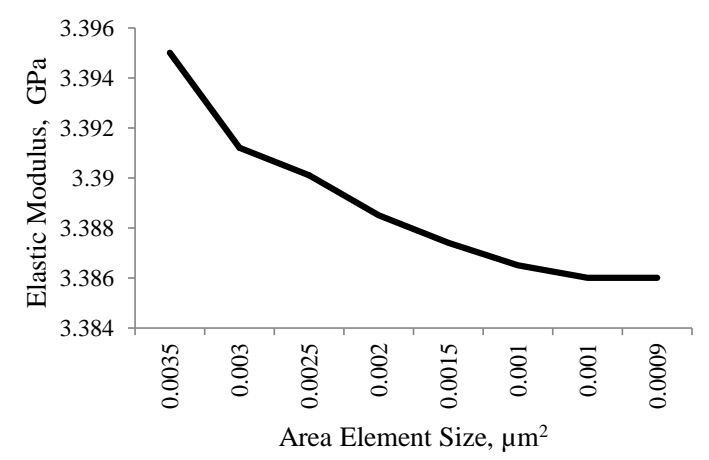

Fig. 4. Mesh convergence plot for single RVE model

The stochastic numerical simulation considers the randomness of the filler in epoxy matrix. The random location of the filler distribution is modelled by using MATLAB code as explained in Section 3.1.

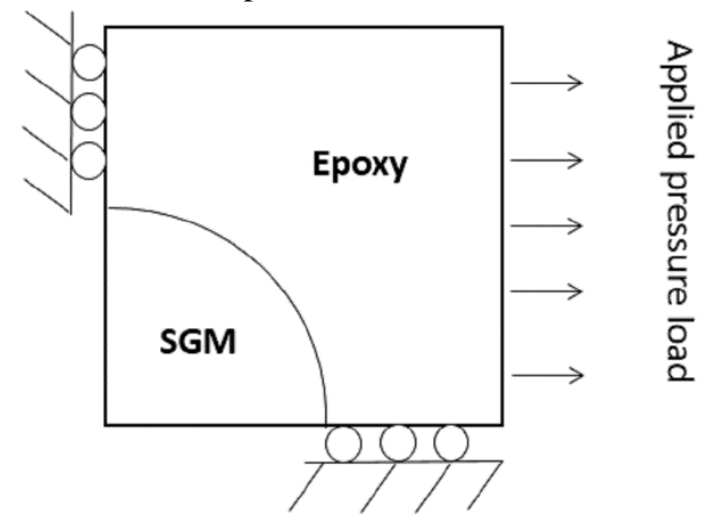

Fig. 5. Loading and boundary condition applied to the single RVE

For definite size of $300 \mu \mathrm{m} \times 300 \mu \mathrm{m}$ square composite, the number of filler particles within the random RVE depends on the volume fractions. The $\mathrm{X}, \mathrm{Y}$ co-ordinate values and Radii values obtained from MATLAB is used for the Numerical analysis. The stochastic based geometric model created in ANSYS is meshed, then the loading and boundary condition is imposed on the finite element model as shown in Fig. 6 and the structural analysis is performed. Further, the effect of interface is also analysed by modeling the interface between the filler and matrix with contact elements.

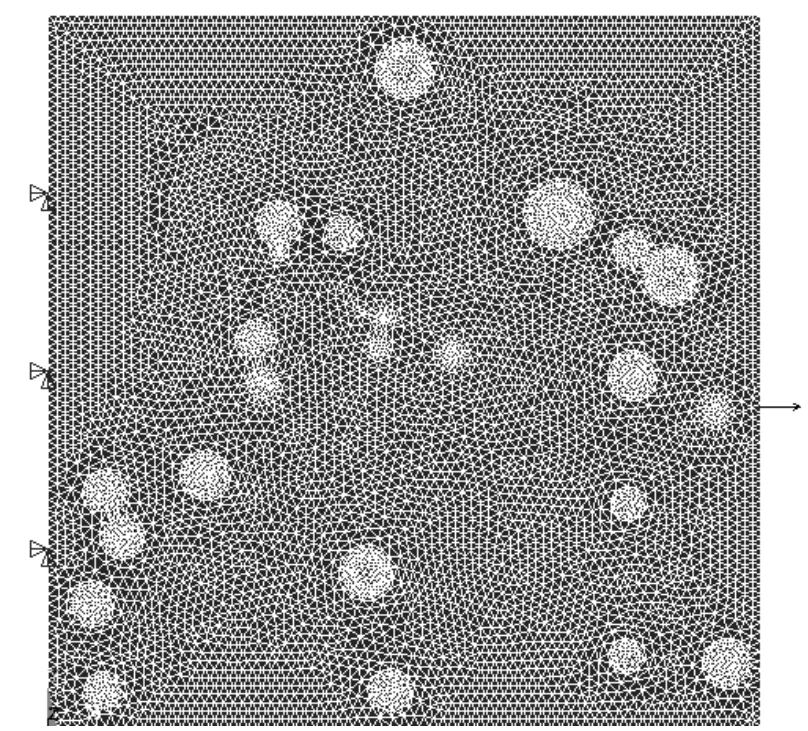

Fig. 6. Loading and boundary condition of the stochastic based model

\section{RESULTS AND DISCUSSION}

The structural analysis of solid glass microsphere filled epoxy is carried out for different filler proportions by considering the particle arrangement as single RVE model and Random RVE model. The volume fractions considered in this study are 5, 10,15 and $20 \%$ of the glass microsphere of $25 \mu \mathrm{m}$ diameter.

Fig. 7 and Fig. 8 shows the stress distribution and the displacement of SGM filled epoxy for the given boundary conditions of a RVE model. From the average stress and strain value obtained the effective modulus and strength are computed. 
Table 2. Comparison of effective elastic modulus of various models

\begin{tabular}{|c|c|c|c|c|c|c|c|c|c|c|c|}
\hline \multirow{3}{*}{ Filler } & \multirow{3}{*}{$\begin{array}{c}\text { Volume } \\
\text { fraction, } V_{f}\end{array}$} & \multicolumn{9}{|c|}{ Elastic modulus, GPa } & \multirow{3}{*}{$\begin{array}{c}\text { Error, \% } \\
\text { Stochastic vs } \\
\text { Experimental } \\
{[14]}\end{array}$} \\
\hline & & \multicolumn{6}{|c|}{ Theoretical } & \multicolumn{2}{|c|}{ Ansys } & \multirow{2}{*}{$\begin{array}{c}\text { Literature } \\
\text { experimental } \\
\text { data }[14]\end{array}$} & \\
\hline & & $\begin{array}{c}\text { Neilsons } \\
\text { model }\end{array}$ & $\begin{array}{c}\text { Einstein's } \\
\text { theory }\end{array}$ & $\begin{array}{l}\text { Voigt } \\
\text { model }\end{array}$ & $\begin{array}{l}\text { Reuss } \\
\text { model }\end{array}$ & $\begin{array}{l}\text { Wong's } \\
\text { model }\end{array}$ & $\begin{array}{l}\text { S-combining } \\
\text { Rule }\end{array}$ & $\begin{array}{l}\text { Single } \\
\text { RVE }\end{array}$ & Stochastic & & \\
\hline Neat & - & 2.45 & 2.45 & 2.45 & 2.45 & 2.45 & 2.45 & - & - & 2.45 & - \\
\hline \multirow{4}{*}{ SGM } & 0.05 & 2.76 & 2.57 & 6.13 & 2.57 & 2.51 & 2.72 & 2.931 & 3.363 & 3.13 & -7.4 \\
\hline & 0.1 & 3.06 & 2.69 & 9.8 & 2.71 & 2.57 & 3.04 & 3.328 & 3.622 & - & - \\
\hline & 0.15 & 3.37 & 2.82 & 13.48 & 2.87 & 2.63 & 3.41 & 3.789 & 4.055 & 3.9 & -3.97 \\
\hline & 0.2 & 3.67 & 2.94 & 17.16 & 3.04 & 2.69 & 3.85 & 4.341 & 4.443 & - & - \\
\hline
\end{tabular}

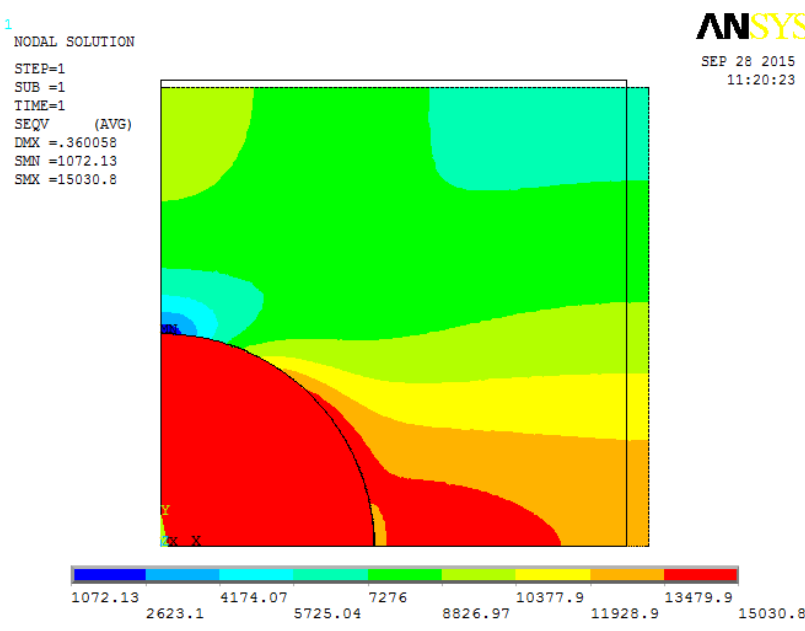

Fig. 7. Stress distribution for RVE model of SGM filled epoxy

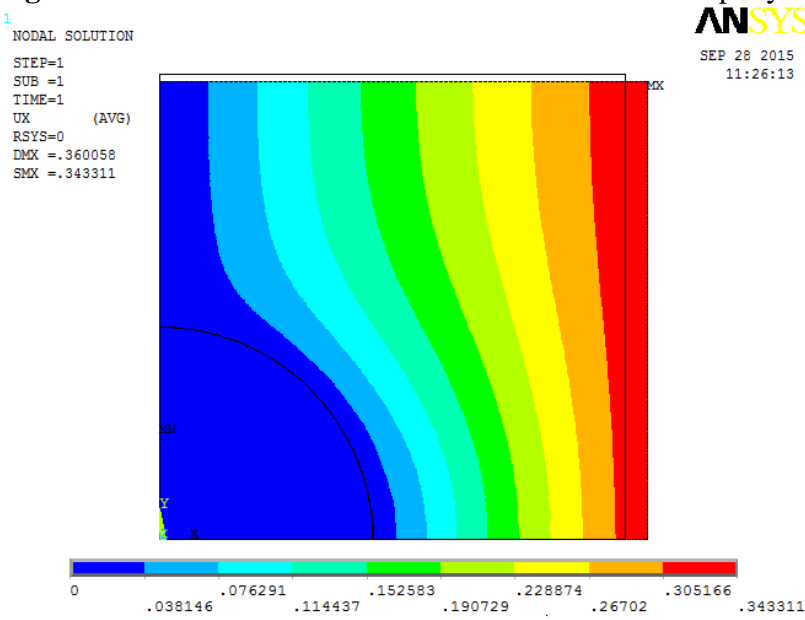

Fig. 8. Displacement for RVE model of SGM filled epoxy

The computed elastic modulus values are compared with different theoretical models, single RVE, Stochastic Model and literature experimental data for a particle size of $25 \mu \mathrm{m}$ diameter are summarised in Table 2 .

Table 2 shows the effect of volume fraction on the effective elastic modulus of SGM filled epoxy composite. From Table 2, it is inferred that as the volume fraction of filler increases the effective elastic modulus also increases. It is also observed that, elastic modulus estimates using numerical simulation methods are found to be within $\pm 10 \%$ of the literature test results. Superior accuracy is observed for S-Combining rule while comparing with other models. Fig. 9 and Fig. 10 shows the stress distribution and the displacement of Stochastic based SGM filled epoxy for the specified boundary conditions.

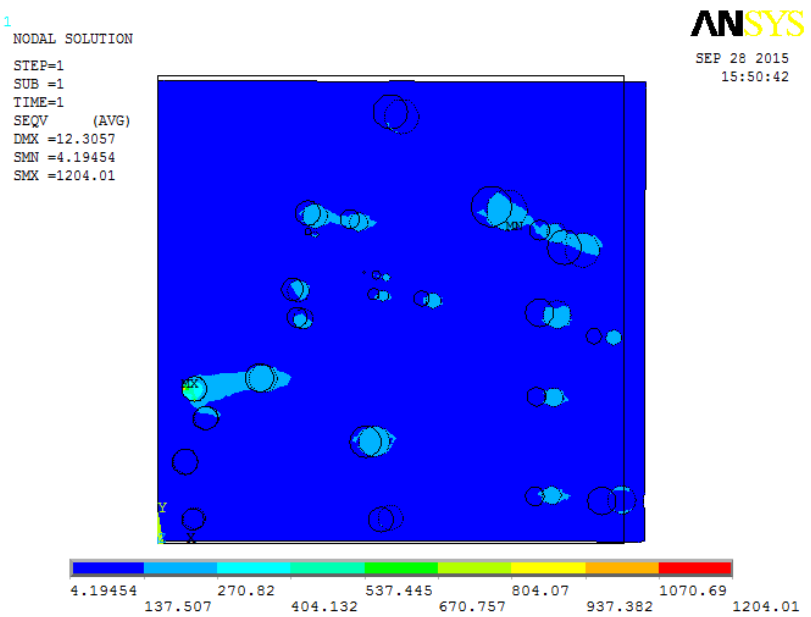

Fig. 9. Stress distribution of stochastic based model

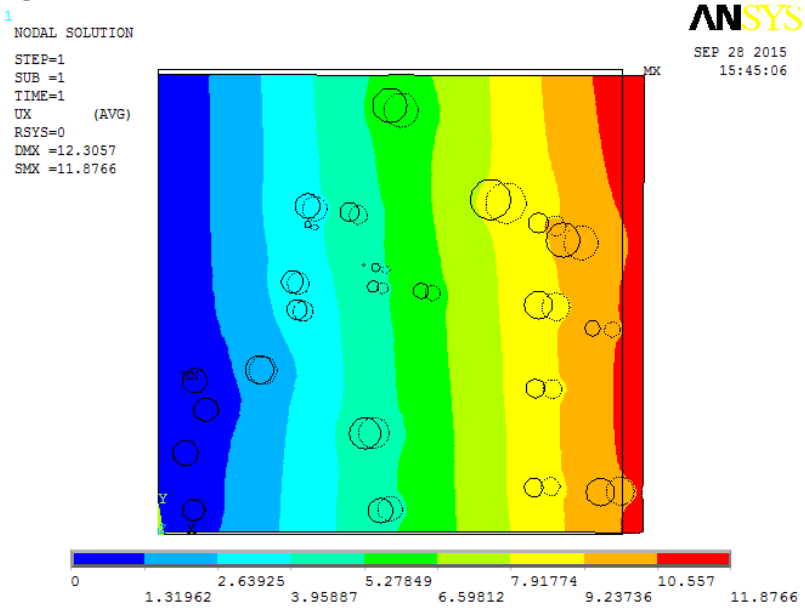

Fig. 10. Displacement of stochastic based model

Later, the effective elastic modulus of solid glass microsphere of various diameters is compared in Table 3.

Table 3. Comparison of effective elastic modulus for various diameter of SGM

\begin{tabular}{|c|c|c|c|c|c|c|c|}
\hline \multirow{2}{*}{ Filler } & \multirow{2}{*}{$\begin{array}{c}\text { Volume } \\
\text { fraction } \\
\%\end{array}$} & \multicolumn{6}{|c|}{$\begin{array}{c}\text { Effective elastic modulus, MPa } \\
\text { Stochastic model-ansys }\end{array}$} \\
\hline & & $\begin{array}{c}\text { dia } \\
25 \mu \mathrm{m}\end{array}$ & $\begin{array}{c}\text { dia } \\
30 \mu \mathrm{m}\end{array}$ & $\begin{array}{c}\text { dia } \\
35 \mu \mathrm{m}\end{array}$ & $\begin{array}{c}\text { dia } \\
40 \mu \mathrm{m}\end{array}$ & $\begin{array}{c}\text { dia } \\
45 \mu \mathrm{m}\end{array}$ & $\begin{array}{c}\text { dia } \\
50 \mu \mathrm{m}\end{array}$ \\
\hline \multirow{4}{*}{ SGM } & 0.05 & 3.363 & 3.574 & 3.567 & 3.573 & 3.581 & 3.385 \\
\hline & 0.1 & 3.622 & 3.559 & 3.576 & 3.623 & 3.601 & 3.554 \\
\hline & 0.15 & 4.055 & 4.403 & 4.506 & 4.477 & 4.462 & 4.486 \\
\hline & 0.2 & 4.443 & 4.772 & 4.636 & 4.745 & 4.723 & 4.619 \\
\hline
\end{tabular}


It clearly shows that, as the diameter of filler increases, the effective elastic modulus also increases linearly. Also for smaller diameter filler, as the volume fraction increases, the effective elastic modulus value increases more gradually than that of higher diameter ranges. Thus from Table 3, it's been clear that the effective elastic modulus increases with the increase in volume fraction and diameter.

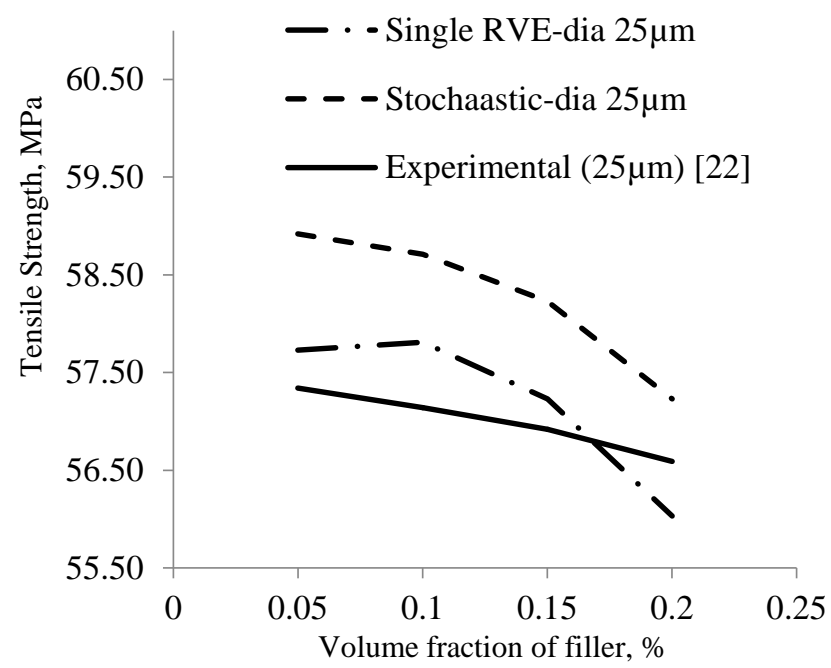

Fig. 11. Comparison of tensile strength of various models

Fig. 11 shows tensile strength of SGM filled epoxies. It is noticed that with addition of SGMs, tensile strength of the composite decreases and this decrement is a function of the SGM content and diameter. This is confirmed with the literature experimental data. Table 4 confirms that the smaller diameter SGM has higher Tensile strength value than that of higher diameter ranges.

Table 4. Effect of SGM filler content in epoxies on tensile strength for various diameters of SGM

\begin{tabular}{|c|c|c|c|c|c|c|c|}
\hline \multirow{4}{*}{ Filler } & \multirow{2}{*}{$\begin{array}{c}\text { Volume } \\
\text { fraction, } \\
\%\end{array}$} & \multicolumn{6}{|c|}{ Tensile strength, MPa } \\
\cline { 3 - 9 } & $\begin{array}{c}\text { dia } \\
25 \mu \mathrm{m}\end{array}$ & $\begin{array}{c}\text { dia } \\
30 \mu \mathrm{m}\end{array}$ & $\begin{array}{c}\text { dia } \\
35 \mu \mathrm{m}\end{array}$ & $\begin{array}{c}\text { dia } \\
40 \mu \mathrm{m}\end{array}$ & $\begin{array}{c}\text { dia } \\
45 \mu \mathrm{m}\end{array}$ & $\begin{array}{c}\text { dia } \\
50 \mu \mathrm{m}\end{array}$ \\
\hline \multirow{4}{*}{ Solid } & 0.05 & 58.92 & 58.73 & 58.59 & 58.42 & 58.21 & 58.01 \\
\cline { 2 - 9 } & 0.1 & 58.71 & 58.52 & 58.21 & 57.81 & 57.62 & 57.21 \\
\cline { 2 - 8 } & 0.15 & 58.23 & 57.92 & 57.44 & 57.1 & 56.93 & 56.43 \\
\cline { 2 - 8 } & 0.2 & 57.23 & 57.1 & 56.94 & 56.42 & 56.19 & 56.12 \\
\hline
\end{tabular}

The present study on stochastic model without considering the interface between filler and matrix over estimates, when compared with literature experimental data [14]. This may be due to the assumption of perfect bonding. In order to simulate the experimental results, the interface region between particle and matrix is to be taken into account. Hence in this study, the structural analysis based on stochastic model with interface is also carried out and the results are summarised in Table 5. Table 5 shows the effect of interface on elastic modulus for the stochastic model. The predicted elastic modulus with interface has good agreement with literature experimental data [14]. From the Table 5, it is also inferred that the error percentage is greatly reduced for lower loading fractions when compared with higher loading fractions. The numerical simulation with interface modeling, exactly simulate the debonding of the particle as shown in Fig. 12 for a loading fraction of $5 \%$.
Table 5. Effect of interface on elastic modulus - Stochastic model

\begin{tabular}{|c|c|c|c|c|c|c|}
\hline \multirow[b]{3}{*}{ Filler } & \multirow{3}{*}{$\begin{array}{c}\text { Volume } \\
\text { fraction, } \\
V_{\mathrm{f}}\end{array}$} & \multicolumn{3}{|c|}{ Elastic modulus, $\mathrm{GPa}$} & \multirow{2}{*}{\multicolumn{2}{|c|}{ Error, \% }} \\
\hline & & \multicolumn{2}{|c|}{ Ansys } & \multirow[b]{2}{*}{$\begin{array}{c}\text { Experimental } \\
{[14]}\end{array}$} & & \\
\hline & & $\begin{array}{c}\text { Stochastic, } \\
\text { WOI }\end{array}$ & $\begin{array}{c}\text { Stochastic } \\
\text { WI }\end{array}$ & & \begin{tabular}{|r} 
Stoch \\
$\mathrm{Vs}$ \\
experir \\
\end{tabular} & $\begin{array}{l}\text { astic } \\
\text { nental }\end{array}$ \\
\hline Neat & - & - & - & 2.45 & WOI & WI \\
\hline \multirow{4}{*}{$\begin{array}{c}\text { Solid } \\
25 \mu \mathrm{m} \\
\text { dia }\end{array}$} & 0.05 & 3.363 & 3.086 & 3.13 & -7.4 & -1.4 \\
\hline & 0.1 & 3.622 & 3.503 & --- & & \\
\hline & 0.15 & 4.055 & 4.019 & 3.9 & -3.9 & -3 \\
\hline & 0.2 & 4.443 & 4.352 & --- & & \\
\hline
\end{tabular}

Thus the numerical simulation with interface modeling is a best alternative to experimental procedure in developing newer materials.This approach also cut down the huge cost for experimentation and the time to market in the design and development of products.

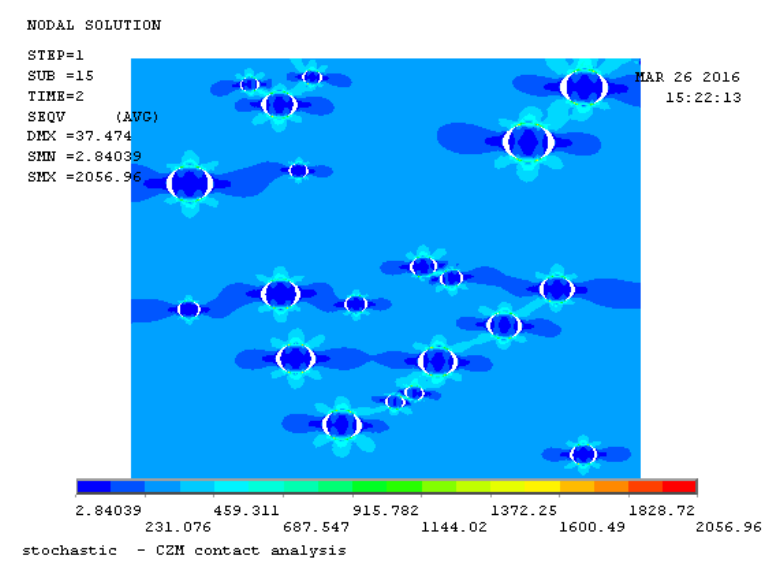

Fig. 12. Particle debonding for loading fraction of $5 \%$

\section{CONCLUSIONS}

1. In this work, the effective elastic modulus of a SGM filled polymeric composites which is used as electronic potting compounds are computed numerically. Through this material characterization, key mechanical properties such as composite modulus and tensile strength are determined. Two different modelling scheme such as single RVE and Stochastic has been used and the observations obtained from this study are summarized as below.

2. Effective Elastic modulus increases with the increase of SGM content in epoxy and it increases with increase of SGM filler size.

3. The Stochastic model with an assumption of perfect bonding between Filler and Epoxy over estimates when compared with the literature experimental data and several mathematical models. This may be due to the fact that bonding is perfect. However closer values are achieved with this model when the interface is exactly modeled. Of the theoretical model investigated, SCombining Rule and C-Combining rules give the closure values of effective elastic modulus.

4. Tensile strength of the composite decreases and this decrement is a function of the SGM content and also it decreases with the increment of filler size. 
5. The stochastic model with interface modeling reduces the error in the prediction.

\section{REFERENCES}

1. Ray, S.S., Okamoto, M. Polymer/Layered Silicate Nano Composites: A Review from Preparation to Processing Progress in Polymer Science 28 2003: pp. 1539-1641.

2. Johnsen, B.B., Kinloch, J., Mohammed, R.D., Taylor, A.C, Sprenger, S. Toughening Mechanisms of Nano Particle-Modified Epoxy Polymers Polymer 48 2007: pp. $530-541$.

3. Kim, M.H., Park, C.I., Choi, W.M., Lee, J.W., Lim, J.G., Park, O.O. Synthesis and Material Properties of Syndiotactic Polystyrene/Organophilic Clay Nano Composites Journal of Applied Polymer Science 92 2004: pp. 2144-2150. https://doi.org/10.1002/app.20186

4. Tyan, H.L., Liu, Y.C., Wei, K.H. Thermally and Mechanically Enhanced Clay/Polyimide Nanocomposite via Reactive Organoclay Chemistry of Materials 11 1999: pp. $1942-1947$.

https://doi.org/10.1021/cm990187x

5. Nakamura, Y., Yamaguchi, M. Effect of Particle Size on the Fracture Toughness of Epoxy Resin Filled with Spherical Silica Polymer 33 1992: pp. 3415-3426.

6. Ma, J., Mo, M.S., Du, X.S., Rosso, P., Friedrich, K., Kuan, H.C. Effect of Inorganic Nanoparticles on Mechanical Property, Fracture Toughness and Toughening Mechanism of Two Epoxy Systems Polymer 49 2008: pp. 3510-3523.

7. Hsieh, T.H., Kinloch, A.J., Masania, K., Taylor, A.C., Sprenger, $\mathbf{S}$. The Mechanisms and Mechanics of the Toughening of Epoxy Polymers Modified with Silica Nano Particles Polymer 51 2010: pp. 6284-6294.

8. Harper, C.A. Electronic Packaging and Interconnection Handbook, McGraw-Hill, NewYork, 2000: pp. 1-1000.

9. Smith, J.C. Experimental Values for the Elastic Constants of a Particulate-Filled Glassy Polymer Journal of Applied Physics and Chemistry 80A 1976: pp. 45-49.

10. Cannillo, V., Bondioli, F., Lusvarghi Montorsi, M., Avella, M., Errico, M., Malinconico, M. Modeling of Ceramic Particles Filled Polymer-Matrix Nano Composites Composites Science and Technology 66 2006: pp. $1030-1037$. https://doi.org/10.1016/j.compscitech.2005.07.030

11. Liu, H., Brinson, L. Mimicking Mussel Adhesion to Improve Interfacial Properties in Composites Composites Science and Technology 68 2008: pp. 2042-2048.

12. Vo, H., Todd, M., Shi, G., Shapiro, A., Edwards, M. Towards Mode L-Based Engineering of Underfill
Materials: CTE Modeling Microelectronics Journal 32 2001: pp. $331-338$ https://doi.org/10.1016/S0026-2692(00)00152-X

13. Brown, D., Marcadon, V., Mele, P., Alberola, N. Effect of Particle Size on the Properties of Model Nano Composites Macromolecules 41 2008: pp. 1499-1511.

14. Matthew Quesenberry, J. Characterization of Low Density Glass Filled Epoxies Army Research Laboratory, Aberdeen Proving Ground 2003: pp. 1-21.

15. Fu, S., Feng, X., Lauke, B., Mai, Y. Effects of Particle Size, Particle/Matrix Interface Adhesion and Particle Loading on Mechanical Properties of Particulate-Polymer Composites Science Direct- Composites: Part B 39 2008: pp. 933-961. https://doi.org/10.1016/j.compositesb.2008.01.002

16. Nassar, A., Nassar, E. Study on Mechanical Properties of Epoxy Polymer Reinforced with Nano SiC Particles Nanoscience and Nanoengineering 1(2) 2013: pp. 189-193.

17. Islam, M.S., Masoodi, R., Rostami, H. The Effect of Nano Particles Percentage on Mechanical Behavior of Silica-Epoxy Nano Composites Journal of Nanoscience 2013: Article ID 275037.

18. Wanga, H.W., Zhou, H.W., Peng, R.D., Leon Mishnaevsky, Jr. Nano Reinforced Polymer Composites: 3D FEM Modeling with Effective Interface Concept Composites Science and Technology 71 2011: pp. 980-988.

19. Wang, Z., Liu, F., Liang, W., Zhou, L. Nanoscale Analysis of Tensile Properties and Fracture of Nano Reinforced Epoxy Polymer using Micromechanics Journal of Reinforced Plastics and Composites 32 (16) 2013: pp. 1224-1233. https://doi.org/10.1177/0731684413486848

20. Hill, R. Continuum Micro-Mechanics of Elastoplastic Polycrystals Journal of the Mechanics and Physics of Solids 13 1965: pp. 89-101. https://doi.org/10.1016/0022-5096(65)90023-2

21. Supriya, S., Selwin Rajadurai, J., Sankar, B. A Numerical Study of Interface Effect on the Effective Thermal Conductivity of Glass Microsphere Filled Polymer Composites International Journal of Applied Engineering Research 10 2015: pp. 8967-8980.

22. Mishra, D. A Study on Thermal and Dielectric Characteristics of Solid Glass Microsphere Filled Epoxy Composites, Ph.D. thesis, National Institute of Technology, Rourkela, 2014. 